\title{
Co-authorship networks: Collaborative research structures at the journal level
}

\author{
Redes de coautoria: Estrutura das colaborações de investigação ao nível de uma revista
}

\author{
José António C. Santos \\ University of Algarve, School of Management, hospitality and Tourism; Research Centre for Sptatial and Organizational Dynamics \\ (CIEO), Campus da Penha, 8005-139 faro, Portugal, jasantos@ualg.pt

\section{Margarida Custódio Santos} \\ University of Algarve, School of Management, hospitality and Tourism; Research Centre for Sptatial and Organizational Dynamics \\ (CIEO), Campus da Penha, 8005-139 faro, Portugal, mmsantos@ualg.pt
}

\begin{abstract}
Present-day research is, in most cases, the outcome of collaborative research, as evidenced by the fact that most papers are authored by two or more researchers. This study's general goal was to examine the evolution and structure of scientific collaborative networks revealed by papers published in the Tourism \& Management Studies journal over a five-year period, from 2011 to 2015, as well as to represent these networks graphically. In this paper, we seek to offer a clear assessment of intra-institutional, inter-institutional and international collaborations and to identify primary author networks and the role of gender in their composition. To reach these goals, we used a combination of bibliometric analysis with social network analysis. The results demonstrate that geographic proximity and linguistic affinity play a substantial role in scientific collaboration between institutions. In fact, most papers result from collaborative research involving two or more authors from the same institution. A gender analysis of the universe of authors and co-authors and of the role of women in the composition of co-authorship networks demonstrated that most networks include women and that, in most networks, women have a leading position, which is consistent with their weight $(51.3 \%)$ in the universe of authors. This is one of the first studies to demonstrate that women are taking the lead in tourism and management research.
\end{abstract}

Keywords: co-authorship networks, collaborative research, research networks, bibliometric analysis, journal analysis.

\section{Resumo}

A investigação científica é, na maioria dos casos, atualmente, o resultado de investigação em colaboração, tal como evidenciado pelo fato de a maioria dos artigos serem da autoria de dois ou mais investigadores. 0 objetivo geral deste estudo é examinar a evolução e a estrutura das redes colaborativas de investigação presentes nos artigos publicados pela revista Tourism \& Management Studies durante o período de cinco anos de 2011 a 2015, assim como representá-las graficamente. Neste artigo, procuramos fazer uma avaliação clara das colaborações intrainstitucionais, interinstitucionais e internacionais e identificar as principais redes de autores, assim como o papel do género na sua composição. Para alcançarmos estes objetivos, usámos uma combinação de análise bibliométrica com análise de redes sociais. Os resultados demonstram que a proximidade geográfica e as afinidades linguísticas têm um papel muito importante na colaboração científica entre as instituições. De fato, a maioria dos artigos resultam de investigação colaborativa envolvendo dois ou mais autores da mesma instituição. Uma análise do género no universo de autores e coautores e o papel das mulheres na composição das redes de coautoria comprovou que a maioria das redes inclui mulheres e que na maioria dessas redes as mulheres desempenham um papel de liderança, o que é consistente com o seu peso $(51,3 \%)$ no universo de autores. Este será um dos primeiros trabalhos a demonstrar que as mulheres estão a assumir um papel de liderança na investigação em turismo e gestão.

Palavras Chave: Redes de coautoria, investigação colaborativa, investigação em rede, análise bibliométrica, análise de revista.

\section{Introduction}

Collaborative scientific research is an important feature of current academic landscapes across disciplines and research fields, in addition to being an important research topic. According to Sonnenwald (2007, p. 645), 'Scientific collaboration can be defined as interaction taking place within a social context among two or more scientists that facilitates the sharing of meaning and completion of tasks with respect to a mutually shared, superordinate goal.' Newman (2004, p. 5200) also expresses a similar view, stating that 'co-authorship of a paper can be thought of as documenting a collaboration between two or more authors, and these collaborations form a co-authorship network'. In these networks, collaboration can be regarded as a strategy to overcome the increasing complexity and specialisation of scientific research, as well as the need for inter- and multidisciplinarity. Complex problemsolving quite often crosses traditional boundaries between academic disciplines or needs to be approached from different perspectives (Hara, Solomon, Kim \& Sonnenwald, 2003; Stevens \& Campion, 1994). Seen from another angle, collaborative research further allows an increase in productivity (Luukkonen, Persson \& Sivertsen, 1992; Price, 1986), which becomes evident when authors collaborate with multiple co-authors or different research teams. Only under these conditions is it possible to optimise efficiency and achieve the highest possible productivity levels.

According to the American Psychological Association (2013, p. 18), 'Individuals should only take authorship credit for work they have actually performed or to which they have substantially contributed.' Hence, authorship implies a 
substantial contribution to the work being published. In addition, 'Principal authorship and the order of authorship credit should accurately reflect the relative contributions of the persons involved' (American Psychological Association, 2013 , p. 19). The principal author, that is, the one who made the most substantial contribution, needs to appear first and the names of co-authors should follow in decreasing order according to the significance of their contribution. However, when all authors have contributed equally significant work, they may agree that their names appear in alphabetical order, or, in the case of authors who repeatedly collaborate, they can take turns being listed first (Day \& Gastel, 2012).

In those situations in which individuals' contributions are not significant, their names should not be listed as co-authors, but simply acknowledged in a note. Unfortunately, there have been cases reported of making colleagues 'honorary coauthors', when they have not actively participated in the research (Katz \& Martin, 1997). This practice may give the wrong impression of collaborative research. Katz and Martin (1997, p. 16) state that, although 'collaboration is conventionally measured through multi-author or multiaddress papers, such an indicator must be treated with caution' because 'there are many cases of collaboration that are not "consummated" in a co-authored paper and which are consequently undetectable with this approach'.

However, co-authorship is still an important indicator of collaborative work and an appropriate means of studying patterns of cooperation in co-authorship networks (Newman, 2004), as 'scientific collaboration is accurately documented in the final product and thus fairly straightforward to assess' (Perc, 2010, p. 476). Therefore, co-authorship is widely used to assess collaborative research (Cimenler, Reeves \& Skvoretz, 2014). Several authors also have referred to the rapid growth of international scientific collaboration (Abbasi, Hossain, Uddin \& Rasmussen, 2011; Luukkonen et al., 1992; Wagner \& Leydesdorf, 2005), stating that, currently, 'most scientific output is a result of group work and most research projects are too large for an individual researcher to perform' (Abbasi et al., 2011, p. 5). Collaboration is, furthermore, a consequence of communication between, and the interactions of, individuals, who represent institutional and global networks (Chinchilla-Rodríguez, Moya-Anegón, VargasQuesada, Corera-Álvarez \& Hassan-Montero, 2008; Kretschmer, 1993; Kyvik \& Larsen, 1994). Studying these author networks contributes to a more comprehensive understanding of their 'collaboration patterns, such as the numbers of papers authors write, how many people they write them with, what the typical distance between scientists is through the network and how patterns of collaboration vary between subjects and over time' ( Newman (2004, p. 5200). Abbasi et al.'s (2011) study provides evidence that researchers who are connected to many distinct scholars receive a higher citation rate than do researchers with fewer connections. Hence, also in terms of performance, it is important to work in effective research networks.

Some authors report that teachers and their students frequently engage in research collaboration (Crane, 1972; Katz
\& Martin, 1997). In the case of master's (MA) and doctoral (PhD) students, such collaborative research normally leads to joint publications. Another important aspect of collaboration between teachers and their former MA and, especially, PhD students is what Crane (1972) calls 'invisible colleges', that is, relationships with high collaboration potential (Katz \& Martin, 1997), which can be materialised in joint publications over time. After graduating, former students tend to attribute their success to their past supervisors and continue regarding them as their 'scientific masters'. Currently, some PhD thesis are designed and developed as a set of papers that have to be accepted and published by refereed journals. It has become commonplace that such papers are jointly authored by students and their supervisors.

Sometimes, geopolitical and historical factors, as well as language, can be factors that influence networks of international scientific collaboration between countries (Luukkonen et al., 1992). In the case of the Tourism \& Management Studies journal, this tendency could explain coauthorship networks that include Brazilian and Portuguese researchers or networks of Portuguese and Spanish researchers, given their cultural proximity and ease of communication. Furthermore, factors such as geographic proximity, linguistic affinity or regional politics may play a considerable role in collaborative research among institutions in a given geographical area (Chinchilla-Rodríguez et al., 2008). Concerning spatial proximity, Katz and Martin (1997) affirm that this tends to generate more informal communication and, hence, encourage academic collaboration. Spatial proximity can strengthen the probability that researchers will develop links through informal communication and even friendship, as they are aware of each other's research interests capabilities. Spatial proximity may have an impact in a wide variety of situations. Sometimes colleagues share the same office where they carry out their academic activities. Along these lines, faculties or schools occasionally create a collective space where researchers work, instead of encouraging their faculty to do their activities in individual offices. This is the case for Haaga Helia University's Porvoo Campus, in Finland. The idea behind this innovative project of designing a new campus with no individual offices for researchers and teaching staff is that working in a collective space fosters communication and teamwork among researchers. In other contexts, spatial proximity can consist of working for the same department, the same research centre or the same institution. In the present research, we sought to explain more fully both patterns of collaboration among researchers from the same institutions and from different institutions.

Tourism research has traditionally been the domain of a 'maledominated gender-blind academic elite' (Figueroa-Domecq, Pritchard, Segovia-Pérez, Morgan \& Villacé-Molinero, 2015). This is clearly the case of decision-making positions in tourism schools and committees, as well as for editorial boards of leading tourism journals (Figueroa-Domecq et al., 2015). Clearly, tourism research occurs in gendered societies, which are ruled by gender relations (Swain, 1995). However, gender equality has legally become the norm in Western societies, and 
women are now occupying important academic positions. Consequently, the number of female authors and co-authors is increasing rapidly, although some authors still find an underrepresentation of women in tourism research (FigueroaDomecq et al., 2015).

Co-authors form a kind of social network, that is, 'a set of actors that are connected to one another through their social ties. Ties are the relationships that connect actors to one another within the network' (Rodway, 2015, p. 6, emphasis in original). In social network analysis (SNA), the entities of a network are called 'actors' and represented graphically as nodes - although sometimes other terms like vertices or points are used - and relationships or ties are represented as edges (Grandjean, 2015). When performing SNA, these and other key concepts must be defined, understood and used consistently throughout studies. There is a vast literature on SNA - not only theoretical works but also studies that apply SNA to various social contexts and different disciplines.

In this paper, we examine the evolution of scientific collaboration networks as revealed by papers published in a journal, in a five-year period from 2011 to 2015. We are aware that 'most authors publish in more than one journal, so that data on publications in a single journal would give an incomplete picture of their authorship patterns' (Newman, 2004, p. 5200). However, as stated previously, we were interested in studying author collaboration patterns only within publications in Tourism \& Management Studies. More precisely, our objectives were:

1. To study evolution over time by the number of papers and authors in a five-year period and the mean number of authors per paper

2. To identify institutions and countries, as well as intra-institutional, inter-institutional and international collaborations

3. To identify the principal networks involved in the publications of Tourism \& Management Studies and represent them graphically, including the collaborators' names, institutions and countries

4. To identify the role of gender in the composition of networks

5. To identify the main keyword categories and how they relate to each other

\section{Methods}

\section{Data collection}

In this study, we combined bibliometric analysis with SNA. Bibliometric analysis is not only applied in library and information sciences for citation and content analysis but also used to evaluate and quantify the growth of publications. In addition, researchers use this method to examine publication characteristics, such as countries, journals, authors, authors' citation habits and research affiliations and keywords (Du, Li, Brown, Peng \& Shuai, 2014). For simple metrics, such as the evolution of publications, number of papers per author, number of authors per paper and authors' affiliation ranked by institution and country, we used descriptive statistics and generated all figures in Microsoft Excel. For more complex SNA, we used SPSS Text Analytics for Surveys. Data had to be prepared to be imported in a suitable format that could be read and interpreted by this programme. This software proved to be appropriate for generating all graphical representations of networks, including author, institution, country and keyword networks. Furthermore, in this study, bibliometric analysis was again proved appropriate for gender research in specific fields (Figueroa-Domecq et al., 2015).

Data were collected manually from nine issues published in a five-year period between 2011 and 2015. The data were then stored in an Excel spreadsheet according to different variables including volume, issue, year, title, language, topic, method, area, keywords, number of authors and institutions and authors' name, gender, institution and country. Given the relatively small number of authors, we had no difficulty identifying their names and institutions. However, in some cases, when the same author had published under different variations of his or her name, it was necessary to standardise authors' names in different papers. The same procedure was necessary for the names of institutions and countries because they appeared in different languages. Concerning paper topics, articles were assigned either to tourism and hospitality or to management. For international collaborations, we considered papers with authors belonging to institutions from two or more countries.

\section{Presentation of Results}

\section{Characterisation of the study universe}

The universe under study is composed of 176 papers published in 3 languages: 83 in English, 62 in Portuguese and 31 in Spanish. Regarding the papers' focus, 110 were on tourism and hospitality and 66 on management. Concerning methods, 128 papers used quantitative methods, 41 used qualitative methods and 7 employed a combination of methods.

\section{Evolution of publications}

Considering the publications' evolution in terms of papers published per year, there was a rapid growth in the number of papers and authors. In 2011, only 14 papers were published, while in 2015, 50 papers were published (see Figure 1), which is an increase of $357 \%$. Regarding the authors involved in publications, in 2011, 42 authors participated, while in 2015, 131 authors published papers in the journal. 
Figure 1: Evolution of the number of papers and authors

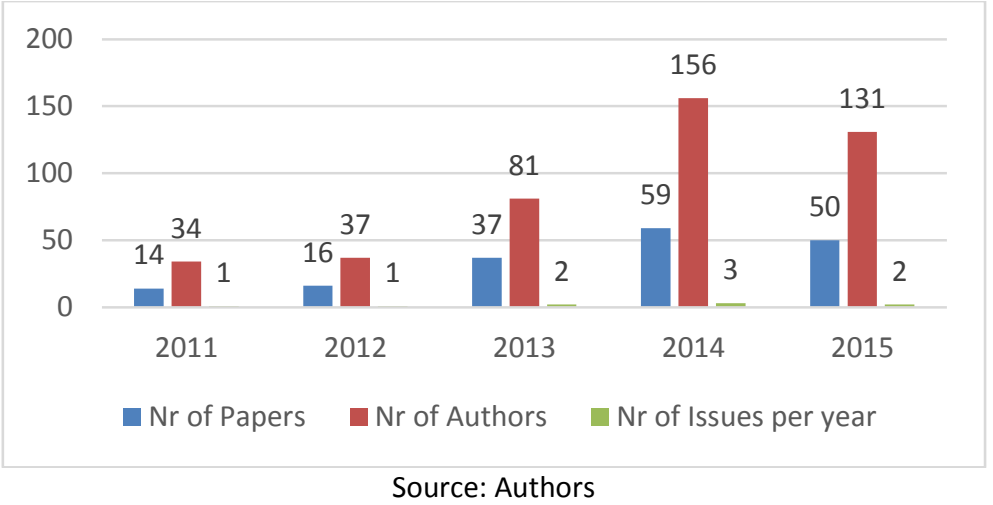

\section{Authors and papers}

The universe of 176 papers involves 439 authors' names. Of these, 309 authors published only once, while 53 other authors published more than one paper. As for the number of papers per author in the universe of authors who published more than one paper, 36 authors published 2 papers each, 13 authors published 3 papers each, 2 authors published 4 papers, 1 author published 5 papers and 1 author published 6 papers.

Regarding the number of authors per paper, 27 papers were single-authored, 64 papers have 2 authors and 62 papers have
3 authors. There are also 17 papers with 4 authors, 6 papers with 5 authors and no papers with more than 5 authors.

\section{Authors' affiliation by institution}

The institutions analysed in this study totalled 122, and they are situated in 18 countries. Among the institutions with the highest number of authors/co-authors are the University of Algarve, ISCTE-IUL, Faculdade Novos Horizontes, University of Málaga, University of Aveiro, University of Seville, University of Extremadura, Southwest University, Polytechnic Institute of Bragança, University of the Vale do Itajaí and the University of Córdoba. For further details, see Figure 2 below.

\section{Figure 2: Institutions with the highest number of authors/co-authors}

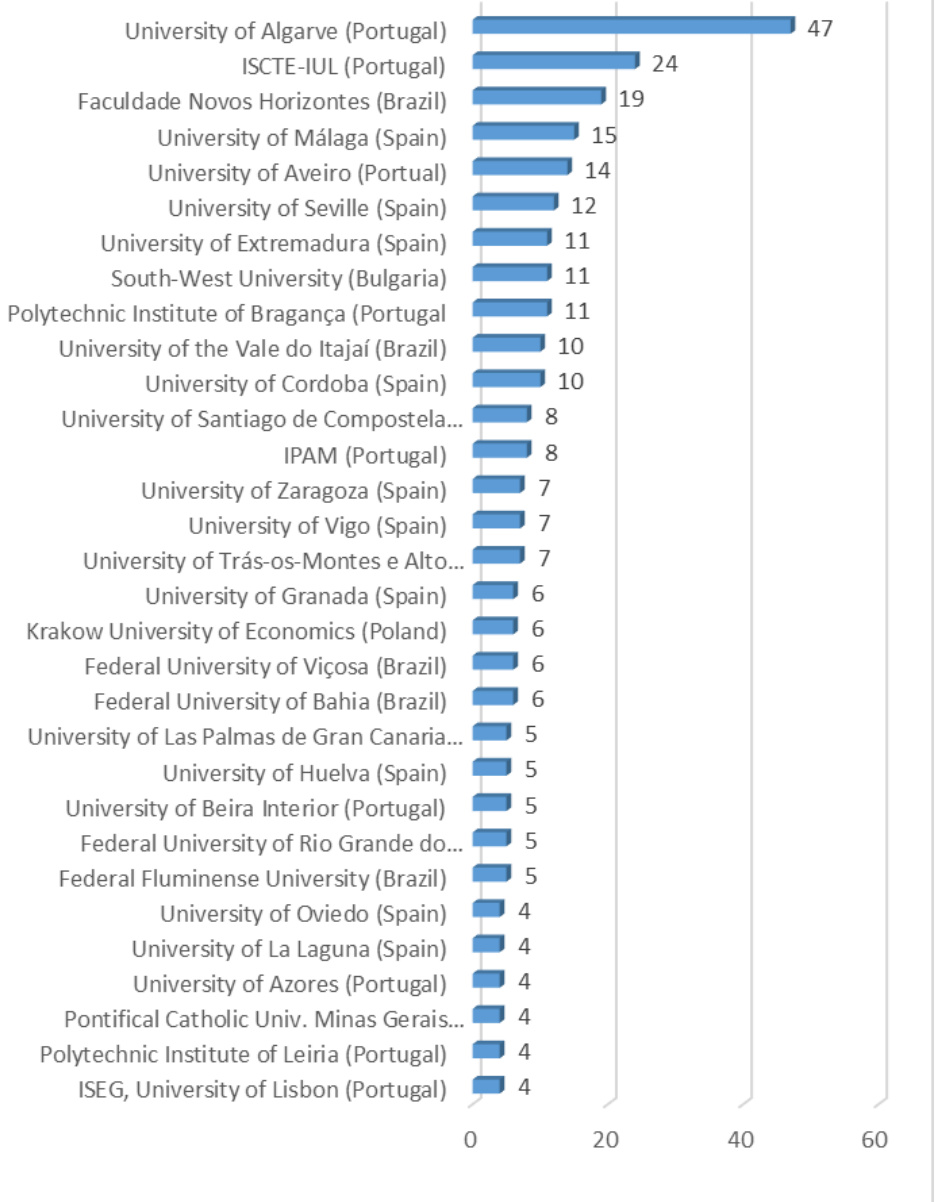




\section{Authors' affiliation by country}

When we focused on the country affiliation of the authors/coauthors, we found that by far the majority of them come from Portugal (162), Spain (126) and Brazil (102). With much smaller numbers, Bulgaria (11), Poland (10), the UK (4), Australia (4), the US (3), the Netherlands (3) and South Africa (3) also appear in the top 10 ranking (see Figure 3 ).

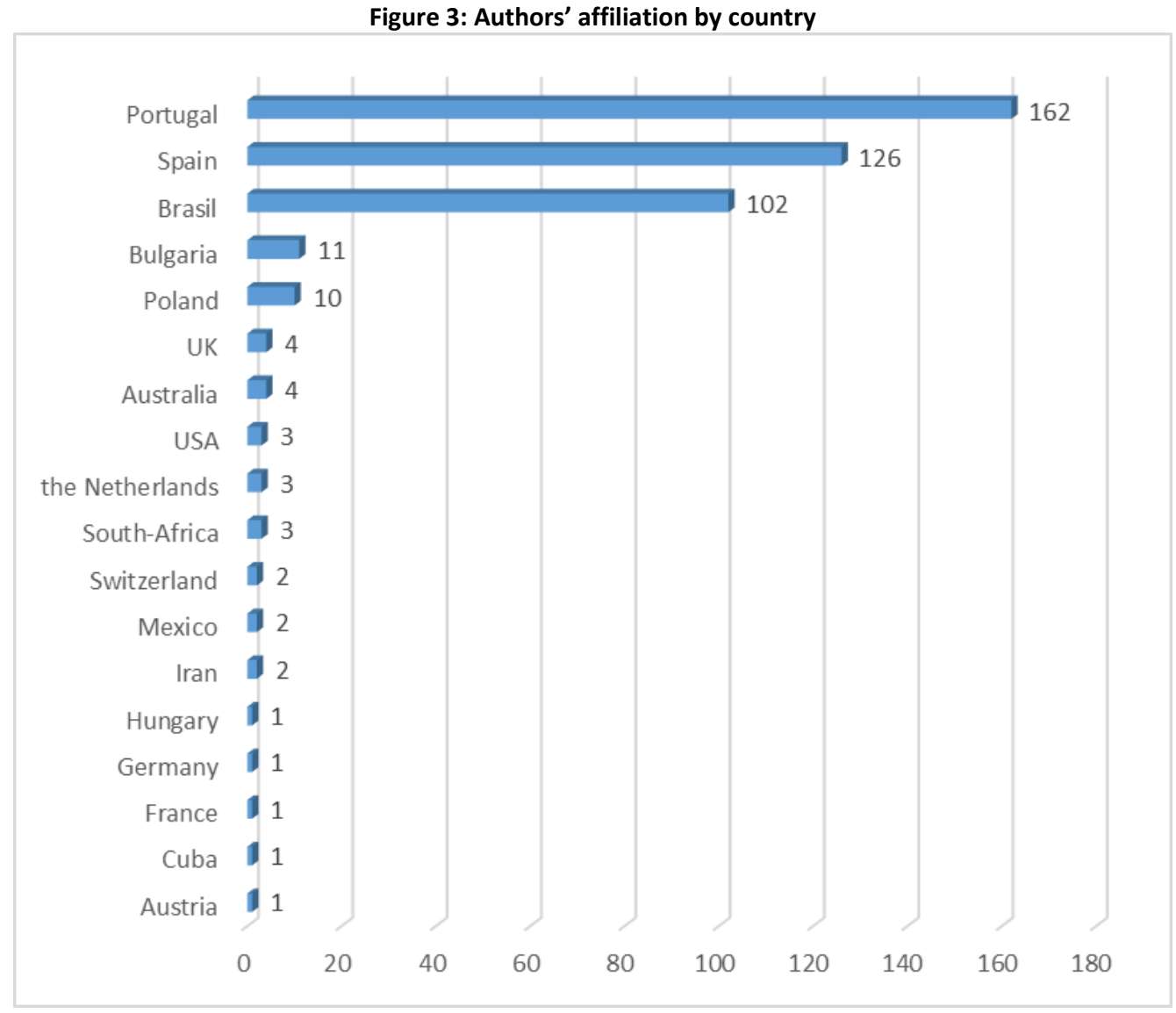

Source: Authors

\section{Intra-institutional and inter-institutional collaboration}

In terms of intra-institutional collaboration - taking into account only papers resulting from multi-authored collaboration $-60 \%$ of papers are co-authored by researchers from the same institution (see Figure 4). We then extended the analysis to inter-institutional collaboration, in which $40 \%$ of papers resulted from the collaboration of authors from different institutions. However, $24 \%$ of those papers with more than one affiliation still include two or more authors from the same institution. In fact, in only $16 \%$ of the papers, all authors belong to different institutions.

Figure 4: Papers resulting from intra- and inter-institutional collaboration

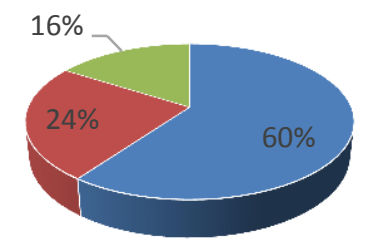

- Papers with all authors from the same institution

- Papers with 2 or more authors from the same institution

- Papers with all authors from different institutions

Source: Authors 
The graphical representation of inter-institutional collaboration networks allows a quick and exact understanding of the ties among institutions based on co-author collaborations. Most collaborative research ties are among institutions of the same country (see Figure 5). That is to say that Portuguese institutions mostly collaborate with other Portuguese institutions, Spanish institutions engage in more collaborations with other Spanish institutions and the same happens for Brazilian institutions. Stronger ties - represented by the edges' (i.e. lines) thickness - are found between institutions of the same country, especially at a regional level and between neighbouring institutions of different countries.
Examples of strong relationships between institutions within the same region or neighbouring regions of the same country are the University of Trás-os-Montes and Alto Douro with the Polytechnic Institute of Viseu (IPV), CEFET Minas Gerais with the Federal University of Minas Gerais and the University of Vigo with the University of Coruña. As examples of strong relationships between institutions of neighbouring regions in different countries, we have the University of Algarve in Portugal with the University of Huelva in Spain and the University of Extremadura in Spain with the University of Beira Interior in Portugal.

Figure 5: Inter-institutional collaboration networks

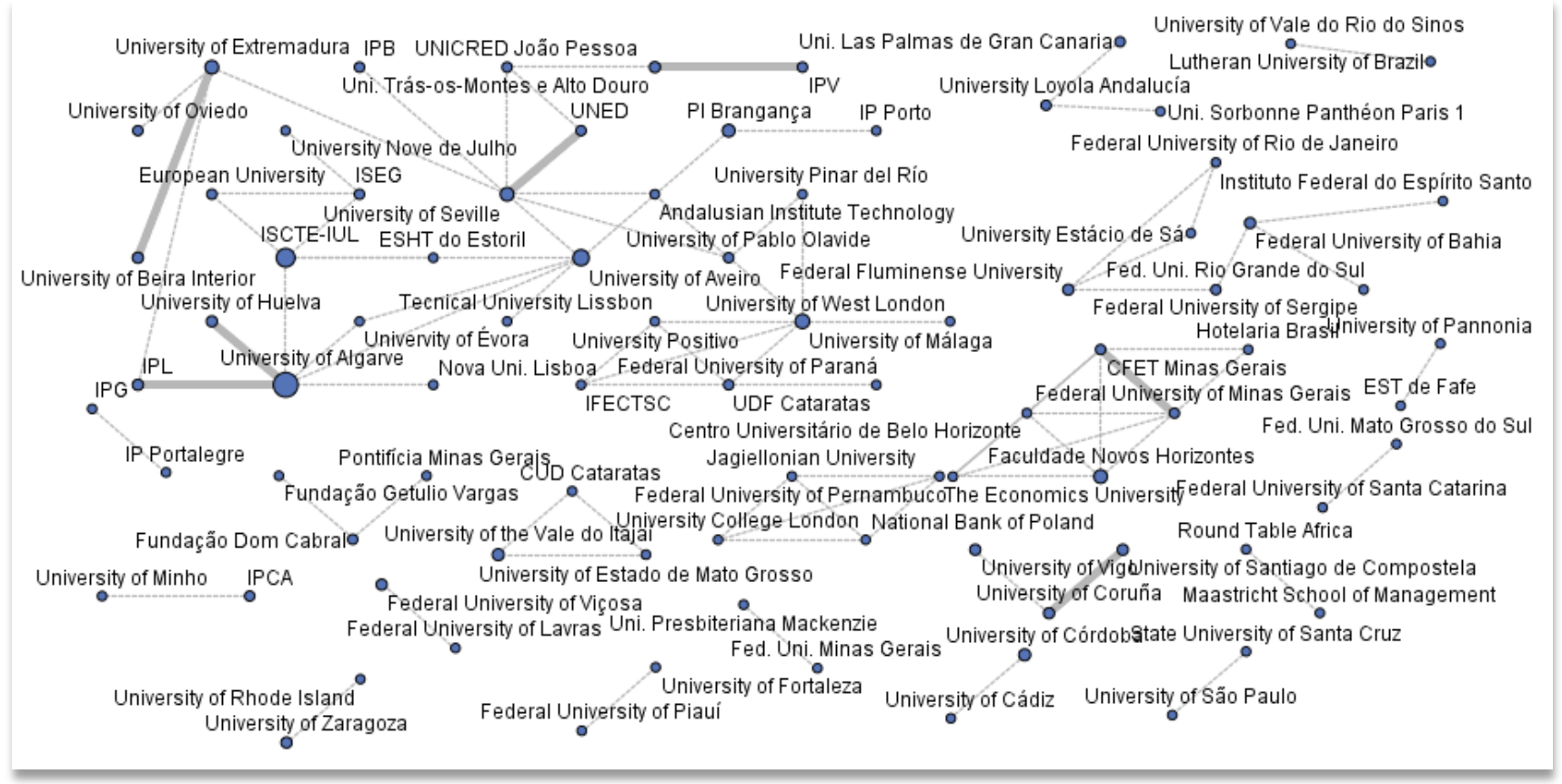

Source: Authors

Concerning international collaboration, that is, when researchers from two or more countries author papers together, 13 papers (i.e. around 7\%) resulted from international research collaboration. At the country level, there is a strong relationship between Spanish and Portuguese authors, with five jointly published papers. Spain shows the best performance in terms of international collaboration as Spanish authors also co-authored papers with authors from Brazil, the UK, Cuba, the US and France (see Figure 6). Portuguese authors published one paper with Brazilian authors and one paper with Hungarian authors. In addition, authors from the UK published a joint paper with authors from Poland.

Figure 6: International networks at the country level

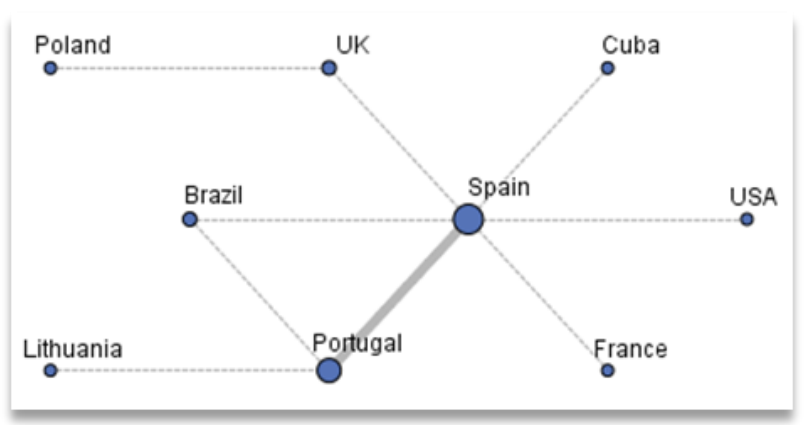

Source: Authors 
Author networks

Figure 7 below shows a cloud representation of the entire author network, which consists of three types of information: authors' names, nodes, which represent authors, and edges, which represent connections between authors (i.e. jointly authored papers). The size of the nodes represents their importance in the network according to the number of coauthored papers, ranging from one to six. Some nodes are clearly bigger, meaning that these actors have authored more papers.

\section{Figure 7: Author network}

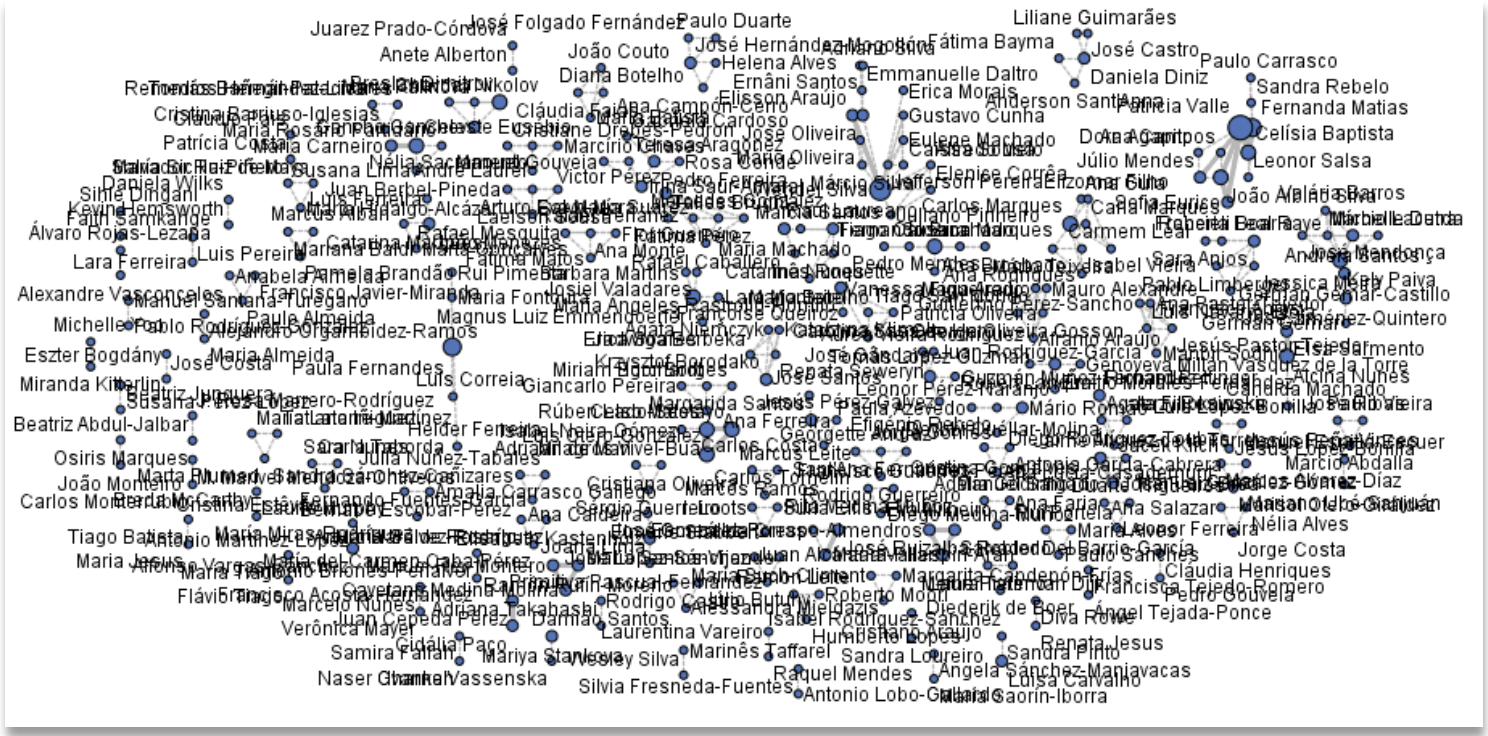

Source: Authors

Figure 8 below represents the main authors' networks with the names of each network's members. In some networks, there is a central node, which has a larger number of direct connections with other network nodes. The advantage of this representation of the main networks is that it allows a quick visualisation of the main actors and their ties with others. The networks' importance lies in the size and number of their nodes and the thickness and number of edges that connect nodes. On a macro level, this graphical representation shows that networks are built around one or more central nodes and that they do not have connections with other networks. Each network is independent from the others, and each can be analysed separately. For instance, Patrícia Valle's network shows a stronger relationship with some network members, such as João Albino Silva, on the one hand, and Fernanda Matias and Celísia Baptista, on the other, meaning that Valle has co-authored multiple papers with these members. Wendel Silva's network has connections with a large number of members, but the edges that connect the nodes are rather thin, meaning that Wendel Silva has co-authored multiple papers with different teams of co-authors and has not published more than one paper with each team.

Figure 8: Main co-author networks

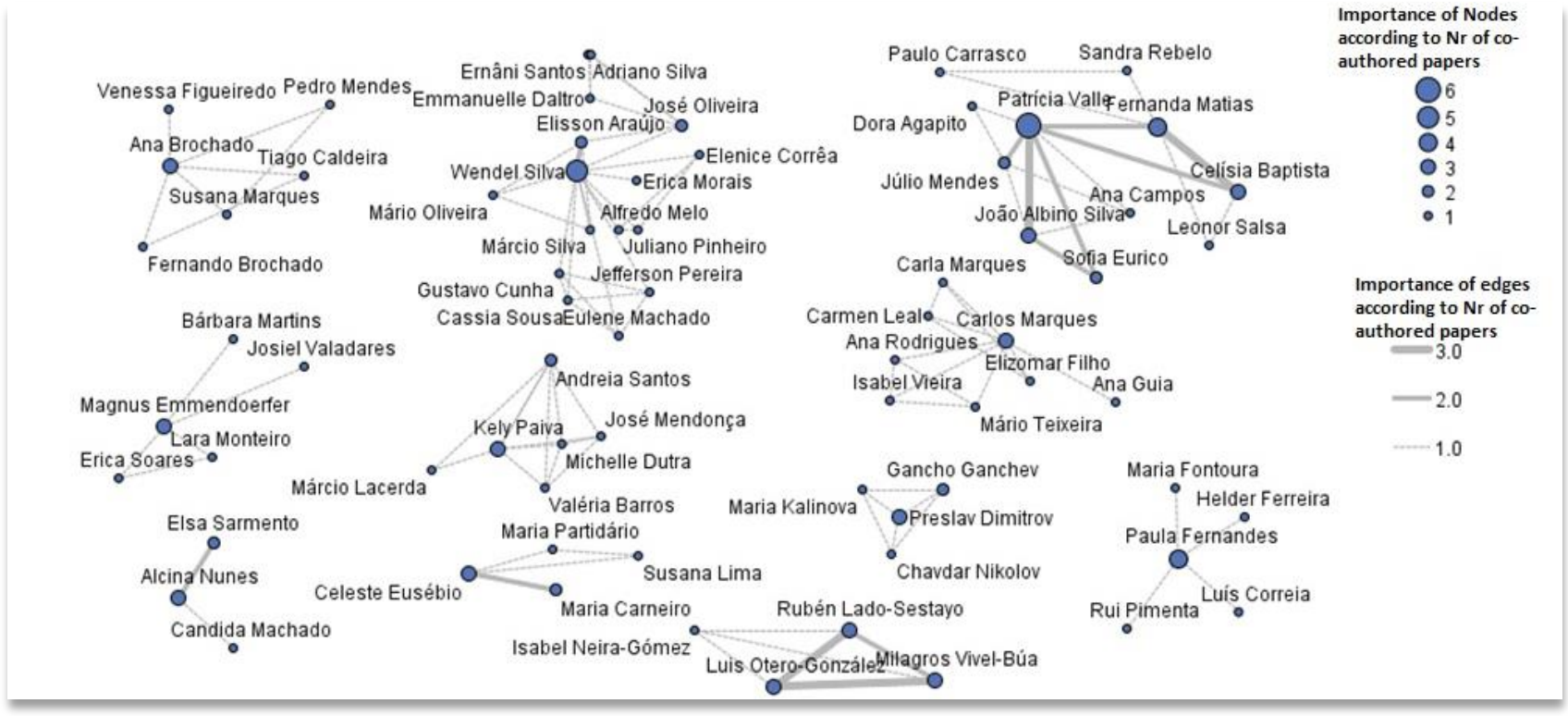

Source: Authors 


\section{Gender}

In terms of gender analysis, all networks depicted in Figure 8 include women, and, in most networks, women have a leading position. This finding is in accordance with the weight of women in the universe of authors/co-authors under analysis, which consists of 225 female authors (51.25\%) and 214 male authors (48.75\%).

\section{Keyword analysis}

The keywords of all the papers were also analysed and grouped into 18 categories, as shown in Figure 9 below. Our main goal was to represent these categories graphically as a network, showing the relationships among them. Using SPSS Text Analysis for Surveys 3.0 allowed us to assess the associations between the afore-mentioned categories, that is, it was possible to pinpoint whether a particular author simultaneously mentioned keywords that refer to category $\mathrm{x}$ and category $y$. The associations' strength is indicated by the frequency, which means that the association between two categories was more significant if a greater number of authors mentioned both categories simultaneously (Santos, 2012).

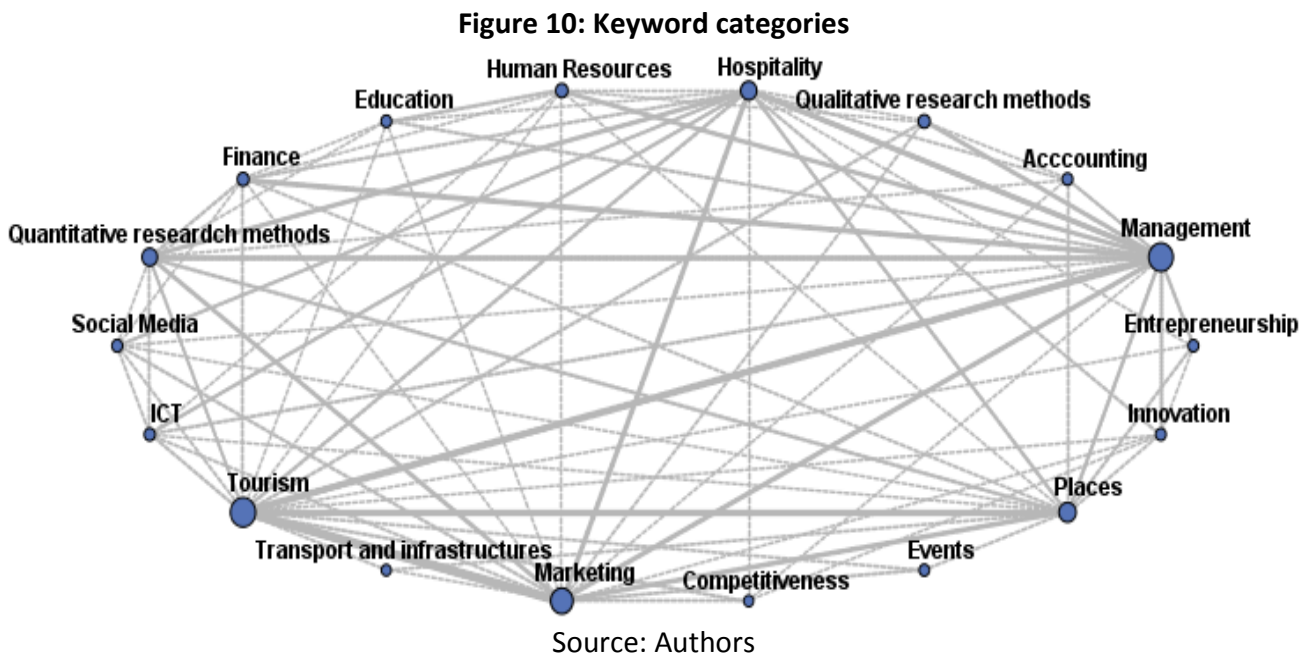

Tourism and management are the strongest keyword groups, with not only the largest nodes but also the strongest relationships. Tourism has extremely strong relationships with marketing and management, a strong relationship with places and a less strong, but still significant, relationship with hospitality. Tourism has weak relationships with all other keyword groups, and no relationship with accounting. Management has a quite strong relationship with tourism, and strong relationships with quantitative research methods, finance, hospitality, human resources and marketing. Management has weak relationships with all other keyword groups, and no relationship with events. Marketing is the third most important keyword group, with extremely strong ties with tourism, as well as places, management, hospitality and quantitative research methods. Marketing has weak relationships with all other keyword groups and no relationship with entrepreneurship. Hospitality is also an important keyword group with strong relationships with management, marketing, and quantitative research methods and less strong, but still significant, ties with social media, information and communications technology, places and tourism. Places is also an important keyword group, which has strong ties with tourism and marketing and significant ties with quantitative research methods, hospitality and management.

\section{Conclusions}

A general conclusion that can be made based on this study's results is that present day scientific studies are primarily the outcome of collaborative research. The discussed findings facilitate a better understanding of publication patterns and the structure of co-author networks in terms of authors, institutions and countries. In addition, keywords also were analysed as networks in order to understand their relative importance in co-author networks and the relationships among keywords. Using a combination of bibliometric analysis and SNA, this study addressed the research objectives clearly and accurately.

Concerning the first objective about the studied journal's evolution over a five-year period - in the number of papers and authors and the mean number of authors per paper - this journal experienced a strong growth in the number of papers published, ranging from 14 in 2011 to 59 in 1014 and dropping to 50 in 2015. This rapid increase in the number of papers can be explained by the following reasons: in 2011 and 2012, the journal still published just one issue per year and started to publish two issues per year from 2013 onwards. The peak reached in 2014 was due to a special issue published in that year. As a consequence of the larger number of papers published, the number of authors also increased from 34 in 2011 to 156 in 2014, dropping to 131 in 2015. Most papers have two or three authors, and the mean number of authors per paper is 2.5. The top five institutions of authors who published in the journal are the University of Algarve, ISCTEIUL, Faculdade Novos Horizontes, the University of Malaga and the University of Aveiro. Regarding the authors' affiliation by country, authors come from 18 different countries, but the greater majority of them come from Portugal, Spain and Brazil.

Our findings confirm Chinchilla-Rodríguez et al.'s (2008) observation that geographic proximity and linguistic affinity play a significant role in scientific collaborations among institutions. In fact, most collaborations occur among 
institutions of the same country, the same region of a given country or between institutions situated in neighbouring regions of different countries. In terms of international collaboration, Spain and Portugal have the strongest ties, with five papers jointly authored by researchers of both countries, but Spain's performance is better, as its authors have made the highest number of connections, that is, joint papers with authors from other countries.

This study identified the main author networks of the journal in question and represented them graphically. The main networks are identified by the names of authors with the highest number of ties with other authors. This is the case of Patrícia Valle and Wendel Silva's networks. However, although all networks show different densities of connections, all have a limited number of connections and function as isolated entities inside the entire collaborative research network. They still have a long way to go before all or at least most networks become interconnected.

A gender analysis of the most important networks showed that all of them include women and that, in most, women have a leading position. This finding is consistent with the weight of women in the universe of authors (51.25\%). These results are valid only for this particular case study and show that, in the case of Tourism \& Management Studies, women are taking the lead in tourism research. Our study does not corroborate the results of a recent gender-focused study by Figueroa-Domecq et al. (2014), which used a universe of 466 papers published in tourism journals in the period of 1985-2012, from the SCOPUS and ISI Web of Knowledge databases. The period under study in the present research, 2011-2015, clearly differs from the period analysed by Figueroa-Domecq et al. (2015). This difference may explain the disparities in the findings and indicate that the patterns of collaborative research are changing significantly. If the first generation of prominent researchers in the tourism field were almost exclusively men (e.g. the membership composition of the International Academy for the Study of Tourism), it is now true that, among the new generations of authors, the proportion of female researchers is higher than ever before. But more genderfocused research is needed to assess the present role of women in tourism and management research more directly.

The keyword analysis revealed that tourism research in the journal under analysis has a very strong relationship with management and marketing. The connection with social sciences such as sociology, psychology or anthropology is weak or even non-existent. Another indicator that reinforces this finding is related to the much stronger representation of quantitative methods $(72.7 \%)$ as compared to qualitative methods (23.3\%) and combinations of methods (4\%).

\section{References}

Abbasi, A., Hossain, L., Uddin, S. \& Rasmussen, K. J. R. (2011). Evolutionary dynamics of scientific collaboration networks: Multilevels and cross-time analysis. Scientometrics, 89, 687-710.
Day, R. \& Gastel, B. (2012). How to write and publish a scientific paper. Cambridge: Cambridge University Press.

American Psychological Association (2013). Publication Manual of the American Psychological Association, Sixth Edition. Washington DC: American Psychological Association.

Chinchilla-Rodríguez, Z., Moya-Anegón, F., Vargas-Quesada, B., CoreraÁlvarez, E. \& Hassan-Montero, Y. (2008). Inter-institutional scientific collaboration: An approach from social network. In Prime Europe-Latin American Conference on Science and Innovation Policy 2008 (pp. 2426). Mexico City: Shawn Harmon School of Law.

Crane, D. (1972). Invisible Colleges. Chicago: University of Chicago Press.

Cimenler, O., Reeves, K. A. \& Skvoretz, J. (2014). A regression analysis of researchers' social network metrics on their citation performance in a college of engineering. Journal of Informetrics, 8, 667-682.

Du, H., Li, N., Brown, M. A., Peng, Y. \& Shuai, Y. (2014). A bibliographic analysis of recent solar energy literatures: The expansion and evolution of a research field. Renewable Energy, 66, 696-706.

Figueroa-Domecq, C., Pritchard, A., Segovia-Pérez, M., Morgan, N. \& Villacé-Molinero, T. (2015). Tourism gender research: A critical accounting. Annals of Tourism Research, 52, 87-103.

Grandjean, Martin (2015). GEPHI: Introduction to network analysis and visualization. Retrieved January 22, 2016 from http://www.martingrandjean.ch/gephi-introduction.

Katz, Sylvan \& Martin, Ben R. (1997). What is research collaboration? Research Policy, 26, 1-18.

Newman, N. M. J. (2004). Coauthorship networks and patterns of scientific collaboration. PNAS, 101(1), 5200-5205. doi: 10.1073/pnas.0307545100

Hara, N., Solomon, P., Kim, S. L. \& Sonnenwald, D. H. (2003). An emerging view of scientific collaboration: Scientists' perspectives on collaboration and factors that impact collaboration. Journal of the American Society for Information Science and Technology, 54(10), 952-965.

Kretschmer, H. (1993). Measurement of social-stratification - A contribution to the dispute on the Ortega Hypothesis. Scientometrics, 26(1), 97-113.

Kyvik, S. \& Larsen, I. M. (1994). International Contact and Research Performance. Scientometrics, 29(1), 161-172.

Luukkonen, T., Persson, O. \& Sivertsen, G. (1992). Understanding patterns of international scientific collaboration. Science, Technology and Human Values, 17(1), 101-126.

Perc, M. (2010). Growth and structure of Slovenia's scientific collaboration network. Informetrics, 4, 475-482.

Price, D. de S. (1986). Little science, big science ... and beyond. New York: Columbia University Press.

Rodway, J. (2015). Connecting the dots: Understanding the flow of research knowledge within a research brokering network. Education Policy Analysis Archives, 23(123), 1-23. doi: 10.14507/epaa.v23.2180.

Santos, M. C. (2012). A importância da paisagem cultural para a competitividade dos destinos [The importance of cultural landscape for the competitiveness of destinations] (Unpublished doctoral dissertation). University of Aveiro, Aveiro, Portugal.

Sonnenwald, Diane H. (2007). Annual Review of Information Science and Technology, 41(1), 643-681.

Stevens, M. J., \& Campion, M. A. (1994). The knowledge, skill, and ability requirement for teamwork: Implications for human resource management. Journal of Management, 20, 503-530.

Swain, M. B. (1995). Gender in Tourism. Annals of Tourism Research, 22(2), 247-266.

Wagner, C. S. \& L. Leydesdorff (2005). Network structure, selforganization, and the growth of international collaboration in science. Research Policy, 34(10), 1608-1618. 